\title{
NOTE
}

\section{Intraspecific co-variation between egg and body size affects fertilisation kinetics of free-spawning marine invertebrates}

\author{
Dustin J. Marshall*, Craig A. Styan, Michael J. Keough \\ Department of Zoology, University of Melbourne, Parkville 3052, Australia
}

\begin{abstract}
Fertilisation of eggs of free-spawning marine invertebrates depends on factors affecting sperm concentration in the field and also on gamete characteristics such as egg size. In the free-spawning intertidal ascidian Pyura stolonifera mean egg size increased with maternal size in 2 separate populations. The largest ascidian produced eggs that were, on average, $50 \%$ greater in volume than the eggs produced by the smallest individual studied. There was no evidence to suggest that egg density varied with adult size and egg dry organic weight increased with maternal size. The fertilisation kinetics of this species were strongly affected by the variation in egg size, with the eggs of large individuals requring much less concentrated sperm to achieve maximal levels of fertilisation success than the eggs of small individuals. We suggest that variation in egg size between individuals of different sizes and ages may be an important factor in determining fertilisation success for ascidians of this species.
\end{abstract}

KEY WORDS: Fertilisation dynamics - Egg size - Ascidian

The rate at which eggs are fertilised can be important in determining the structure and dynamics of freespawning marine invertebrate populations (Levitan 1995, Levitan \& Petersen 1995). A key factor affecting fertilisation success is the ambient sperm concentration into which released eggs are exposed. Consequently, factors that affect sperm concentration such as hydrodynamic conditions (e.g. Denny \& Shibata 1989), gamete viscosity (Thomas 1994a,b), and the population size, density and dispersion of male spawners (e.g Pennington 1985, Yund 1990, Levitan 1991, Levitan et al. 1992, Levitan \& Young 1995, Coma \& Lasker 1997) can all, in turn, affect the dynamics of fertilisation. Gamete characteristics, such as egg size, may also have an influence on fertilisation dynamics (Levitan 1993,

·E-mail: d.marshall@zoology.unimelb.edu.au 1996a, Podolsky \& Strathmann 1996, Styan 1998), essentially because egg size should determine the size of the 'target' area that is available for searching sperm to find. Larger eggs should therefore be encountered by sperm at higher rates, thus increasing fertilization rates. However, if eggs are too large and in sperm excess conditions, they may also become more likely to be contacted by multiple, coincident sperm and become polyspermic (Styan 1998). Nonetheless, Levitan (1996b) demonstrated that, in sperm-limiting conditions, even small differences in egg size can result in differential fertilisation, with larger eggs within a spawn more likely to be fertilised than small eggs. Moreover, Levitan (1998) found that, amongst strongylocentrotid urchins, fertilisation worked more effectively, in the face of rapid dilution of sperm in the field, for the urchin species with the largest eggs.

It appears that egg size is related to maternal size in many species of fish (e.g. Baynes \& Howell 1996, Kerrigan 1997), but, whilst several studies have noted maternal-size-associated differences in egg size between populations of marine invertebrates (e.g. George 1994a,b, Bertram \& Strathmann 1998), almost none have examined how much variation in egg size occurs within populations (but see George 1999). We determined the existence and importance of variation in egg size in a marine invertebrate that reproduces by broadcasting eggs and sperm. The solitary ascidian Pyura stolonifera is a common intertidal and shallow subtidal invertebrate found along the open coast of southern Australia (Kott 1997). First, we describe variation in egg size within populations of this species, and ask whether a relationship between maternal size and egg size exists. Second, we ask what the likely consequences of the variation in egg size for the dynamics of external fertilisation are. 
Materials and methods. Pyura stolonifera were collected intertidally from 2 sites on the west coast of Victoria, in south-eastern Australia. P. stolonifera individuals from a population at Barwon Heads were collected on January 15, and used to measure egg size. Other ascidians were collected from a population approximately $50 \mathrm{~km}$ away at Lorne on January 24 and used for egg size measurements and to examine fertilisation kinetics. Prior to use, $P$. stolonifera were maintained in $40 \mathrm{l}$ flow-through tanks at a constant temperature of $15^{\circ} \mathrm{C}$. All investigations were done on $P$. stolonifera during their spawning season and, according to gonad indices, very close to time of spawning in the field (Marshall unpubl. data). We removed by dissection the gonad and visceral mass of each $P$. stolonifera, both of which are easily distinguishable. These were blotted on absorbent paper and (wet) weights of the viscera and gonad recorded.

Pyura stolonifera were stripped of eggs and 100 randomly selected eggs from each $P$. stolonifera were videotaped under $80 \times$ magnification. These images were digitised using a frame-grabber and we measured egg diameter using SigmaScan (Jandel Scientific, Ver. 3). Measurement of egg size was repeated for 21 P. stolonifera from Barwon Heads and 17 P. stolonifera from Lorne. Egg size data from each P. stolonifera were checked for normality and mean egg diameter for each $P$. stolonifera population was regressed against maternal visceral mass.

We were interested in whether the observed differences in egg size between individuals reflected differences in organic investment per egg between individuals or the observed relationship was due to differences in the degree to which eggs were hydrated. Accordingly, we measured the dry organic weight of eggs from Pyura stolonifera across a range of sizes. Eggs were obtained and measured, as described above, from 10 haphazardly selected $P$. stolonifera. Fifty eggs from each individual were then rinsed with ammonium formate $(3.4 \% \mathrm{w} / \mathrm{v})$ to remove inorganic salts and placed on pre-weighed pieces of filter paper. We placed these in a drying oven at $45^{\circ} \mathrm{C}$ until there was no change in weight. The average organic weight per egg was then calculated for each $P$. stolonifera and this value was regressed against maternal visceral mass. In addition, we used dry organic weight and egg volume (calculated from size measurements) to calculate the organic density of the eggs and this value was also regressed against maternal visceral mass.

We found that egg size increased with body size and therefore were interested in whether fertilisation kinetics of eggs also varied with maternal body size. To investigate this, we examined how fertilisation success varied with sperm concentration and how this relationship changed with maternal body size.
Egg solutions were prepared first (eggs collected as described above) and maintained in seawater at room temperature $\left(-22^{\circ} \mathrm{C}\right)$. Sperm was then obtained from haphazardly selected Pyura stolonifera by removing the gonad by dissection, and macerating the regions containing sperm. Sperm concentrations were kept as concentrated (dry) as possible to minimise the possible effects of sperm ageing. In all trials, eggs and sperm were used within 10 and $2 \mathrm{~min}$ of collection respectively. Different (non-self) sperm and egg donors were used in each cross. The 'dry' sperm solution was used to create 3 replicate series of 8,10 -fold dilutions $\left(10^{0}, 10^{-1}\right.$, $10^{-2}, 10^{-3}, 10^{-4}, 10^{-5}, 10^{-6}, 10^{-7}$ the concentration of the stock solution). A $1 \mathrm{ml}$ subsample of the $10^{-2}$ dilution was taken to estimate absolute sperm concentration (3 replicate counts using a haemocytometer).

Nine $\mathrm{ml}$ of each sperm concentration was pipetted into a series of $30 \mathrm{ml}$ plastic test tubes, and as a control for errant fertilisations caused by contamination with sperm from the egg donor, $9 \mathrm{ml}$ of sperm-free seawater was pipetted into a control test tube. One $\mathrm{ml}$ of fresh egg solution (approx. 1000 eggs $\mathrm{ml}^{-1}$ ) was immediately added to each test tube. Eggs were left at room temperature for $2 \mathrm{~h}$ to develop and then were fixed with a few drops of formalin. Later, 100 eggs from each replicate at every sperm concentration and control tube were assayed under $80 \times$ magnification and scored as either 'developing normally' (eggs showing normal cell division) or 'not developing normally' (eggs showing no cleavage or showing abnormal cell division). It was difficult to discriminate between unfertilised eggs and polyspermic eggs because pilot studies showed that only a small proportion $(<5 \%$ Marshall unpubl. data, see also Lambert \& Lambert 1981) of polyspermic Pyura stolonifera eggs ever show any development. abnormal or otherwise.

Fertilisation success was calculated for each sperm concentration and the mean of the 3 replicates at each sperm concentration was determined for each assay. Any assay where errant fertilisations occurred at greater than $1 \%$ were discarded from further analysis (4 trials). We plotted mean fertilisation success against sperm concentration and produced a fertilisation curve for each Pyura stolonifera individual's batch of eggs. From these curves, we recorded the sperm concentration where the maximum number of eggs were fertilised for each batch of eggs and regressed this value against maternal visceral mass.

Results. Large Pyura stolonifera produced larger eggs than smaller individuals. Mean egg diameter increased with individual body mass at both sites (Barwon Heads: $R^{2}=0.725, n=21$; Lorne: $R^{2}=0.678, n=17$; Fig. 1), and the largest $P$. stolonifera in this study produced eggs that were $50 \%$ greater in volume than the eggs produced by the smallest $P$. stolonifera. The pre- 


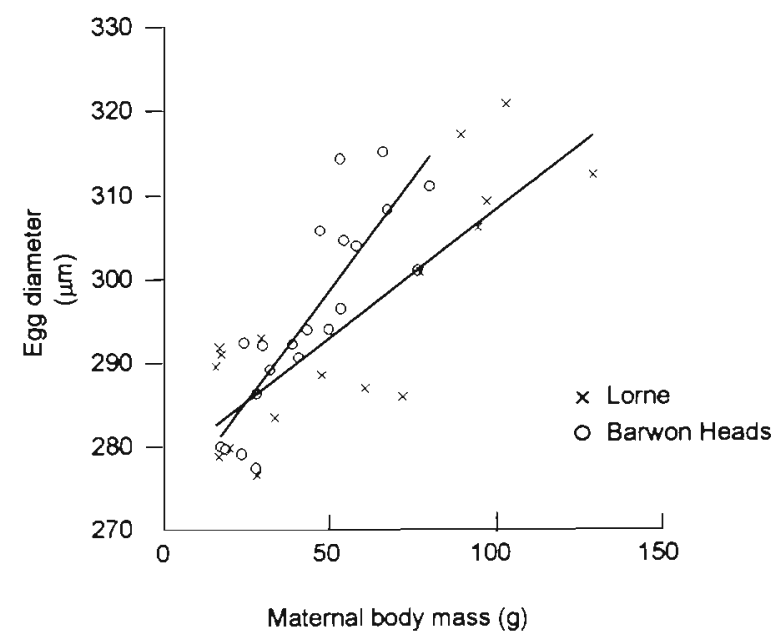

Fig. 1. Pyura stolonifera. Relationship between mean egg diameter and maternal body size for Barwon Heads (15 January 1999) and Lorne (25 January 1999) populations. Regression for Barwon Heads: egg diameter $=0.526$ body mass $+272.3, \mathrm{p}<0.001, \mathrm{n}=21$; Lorne: egg diameter $=0.303$ body mass $+277.8, \mathrm{p}<0.001, \mathrm{n}=17$

cise relationship between egg size and maternal mass did, however, vary between the 2 sites (analysis of covariance, comparison of regression slopes, $F_{1,34}=$ 5.961, $\mathrm{p}=0.02$ ). Mean organic weight of eggs also increased with body mass $\left(\mathrm{R}^{2}=0.918, \mathrm{p}<0.001, \mathrm{n}=\right.$ 10). The organic density of eggs was unrelated to maternal size $\left(\mathrm{R}^{2}=0.219, \mathrm{p}>0.1, \mathrm{n}=10\right)$ Eggs also varied in size within broods with smaller $P$. stolonifera showing more variation in the sizes of eggs produced than larger individuals. Specifically, variance in the size of eggs decreased with increasing body mass at Barwon Heads with a similar (though non-significant) trend at Lorne (Barwon Heads: $\mathrm{R}^{2}=0.294, \mathrm{p}=0.011$, $\mathrm{n}=21$; Lorne: $\mathrm{R}^{2}=0.206, \mathrm{p}=0.068$ )

Maximum fertilisation success experienced by eggs (egg viability) varied substantially between individuals but was unrelated to adult size $\left(\mathrm{R}^{2}<0.001, \mathrm{p}=0.917, \mathrm{n}=\right.$ 21). Fertilization rate for most individuals was low when sperm concentrations were low, rose rapidly with increasing sperm concentration, and then fell of sharply (Fig. 2a). The ' $F_{\text {max' }}$ ' sperm concentration, i.e. that which maximised fertilisation rates for each individual, fell sharply with increasing adult size (Fig. 2b). This was represented by the shift to the left of fertilisation curves for eggs from Pyura stolonifera of increasing size (Fig. 2a). The eggs of the largest $P$. stolonifera were maximally fertilised at a sperm concentration 3 orders of magnitude less than that for the smallest individuals.

Discussion. Within both populations of Pyura stolonifera in this study, egg size varied markedly among individual ascidians, and mean egg size increased with maternal body size. Eggs also varied in size within

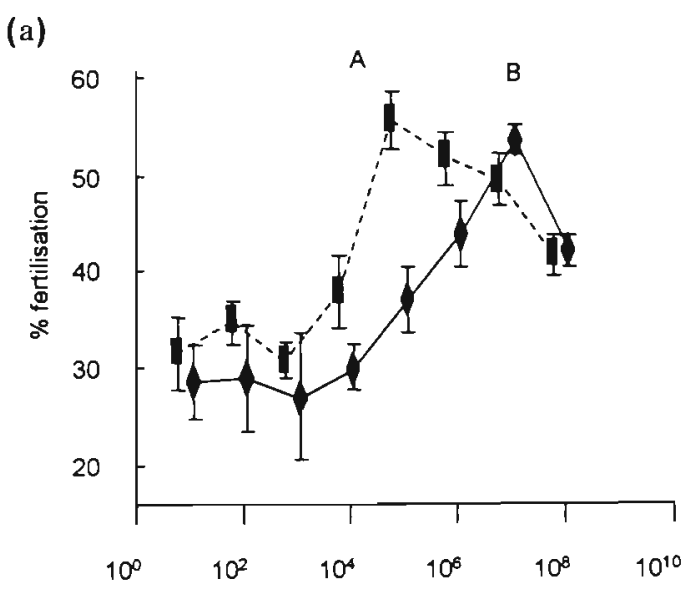

Sperm concentration (sperm $\mathrm{ml}^{-1}$ )

(b)

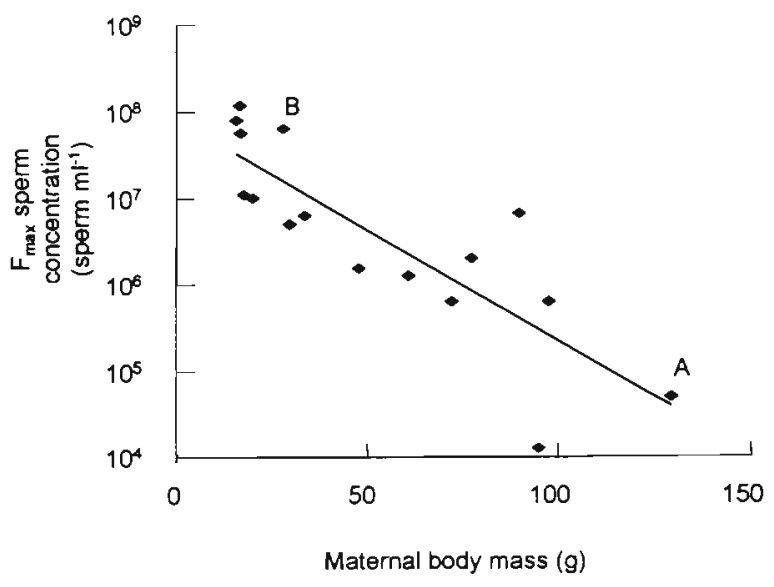

Fig. 2. Pyura stolonifera. (a) Fertilisation curves for the eggs of a representative large (A) and small (B) ascidians. (b) Relationship between maternal body size and the sperm concentration where fertilisation success is maximised for Lorne (25 January 1999) population of $P$. stolonifera. Regression for log sperm concentration and maternal body mass: $\mathrm{R}^{2}=0.654, \mathrm{p}<0.001, \mathrm{n}=17$

individual clutches. For this ascidian, increases in gamete investment do not necessarily result in an increase in simply the number of eggs produced, but egg characteristics such as size can also change.

Location, maternal nutrition and spawning history are known to markedly influence the egg size of marine invertebrates (e.g. Chester 1996, Jones et al. 1996, Bertram \& Strathmann 1998). Whether the differences we found across sizes and locations reflect differences in nutrition or spawning history is unknown, but we found similar trends in egg size in the 2 intertidal populations, suggesting that any causal factors act within and between populations. Whatever the causal mechanisms, our work suggests that the size distribution of 
eggs released during spawning will be determined by the size structure, and, to a lesser extent, location of populations. Egg size variation may have consequences for larval survival and settlement success. Experimental reduction of egg volume has been shown to increase development time, lower larval feeding rates and reduce post-settlement performance (Sinervo \& McEdward 1988, Hart 1995, Emlet \& Hoegh-Guldberg 1997 ). Furthermore, Bertram \& Strathmann (1998) found that natural variation in egg size between different populations of sea urchins was sufficient to generate differences in larval development times. Dry organic weight of eggs has been shown to be strongly correlated with energy content for a number of different species (Jaeckle 1995). Although not directly measured here, it seems likely that the eggs of large Pyura stolonifera contained more energy reserves than the eggs of small $P$. stolonifera. Thus, we suggest that the larvae of large P. stolonifera may have greater chances of settling successfully than the larvae of small $P$. stolonifera. This prediction awaits further testing.

A further consequence of maternally associated variation in egg size was that eggs of large and small Pyura stolonifera differed in their fertilisation characteristics. Large eggs from large P. stolonifera required much lower sperm concentrations to achieve a high rate of fertilisation than the smaller eggs of small $P$. stolonifera. Additionally, putative polyspermy effects (defined here as decreasing fertilisation with increases in sperm concentration) occurred at lower sperm concentrations with the eggs of large $P$. stolonifera, than the eggs of small individuals. The mechanism causing these different fertilization curves cannot be determined without exact knowledge of sperm-egg collision rates. Theoretical modelling has shown that egg size should affect the likelihood of eggs encountering sperm, and thus fertilisation and the likelihood of polyspermy in the ways observed here (Levitan 1993. Styan 1998), but it is also possible that the proportion of sperm-egg contacts that are fertilising may vary with egg size (Styan \& Butler in press). The maximum fertilisation success for any batch of eggs never exceeded $80 \%$. This is in keeping with the prediction of Styan's (1998) model that without a highly efficient polyspermy block, fertilisation success can never reach $100 \%$. Lambert \& Lambert (1981) found that the eggs of the ascidian Ascidia nigra took approximately $21 \mathrm{~s}$ to form a block to additional sperm after the first fertilisation. It appears likely therefore that a slow polyspermy block is responsible for less than 100\% fertilisation success observed here. However, it is possible that not all the eggs in any batch were viable.

These effects of variation in egg size on fertilisation may affect the relative reproductive success of different sized spawning individuals within local popula- tions. When sperm concentrations are relatively low, eggs of larger Pyura stolonifera may have a greater chance of being fertilised in the sperm-limited conditions than the smaller eggs produced by small $P$. stolonifera. Conversely, if sperm concentration is high, smaller eggs from small $P$. stolonifera will be more successfully fertilised than eggs from larger $P$. stolonifera, which would suffer from polyspermy more frequently. However, predicting exactly how egg size variation will interact with the sperm environment in real spawning events is difficult and requires more fieldbased information, especially about the sperm environment in which eggs are likely to be released. In the wave-swept intertidal areas where $P$. stolonifera are found, sperm concentrations could typically be both very high or very low, depending on exactly when, where and how many ascidians spawn.

On exposed shores subject to turbulent wave action, sperm dilution can be very great even over small spatial and temporal time scales (Denny \& Shibata 1989). Alternatively, sperm dilution may not be great if Pyura stolonifera spawn only at low tide, or in calm conditions, a strategy utilised by some fucoid algae to ensure high rates of fertilisation (Serrao et al. 1996). Individuals of $P$. stolonifera have been reported anecdotally as spawning simultaneously at low tide on 1 shore in this area (Dalby 1995b). Sperm may also not spread rapidly if they are released in a viscous matrix (e.g. Thomas $1994 \mathrm{a}, \mathrm{b})$, or if they are released within the relatively non-diluting conditions of surge channels or rock pools (Denny et al. 1992). The final factor likely to affect the concentration of sperm is the local density of adults. These ascidians range from isolated individuals metres from a neighbour, to sparse individuals separated by a few centimetres, to dense beds. Dense beds are a common occurrence along the east coast of Australia (Fairweather 1991, Underwood 1994), while along the south coast, sparse beds are common, although dense beds do occur (Bennett \& Pope 1953, Dalby 1995b). Under these circumstances, we may find some sections on rocky shore favouring fertilisation success for ascidians that produce small eggs, while other nearby areas may favour the fertilisation of larger eggs. One intriguing possibility is that the mean size of individuals might be density-dependent (e.g. Dalby 1995a), in which case densely packed individuals might produce smaller eggs, which would in turn be successfully fertilised in high local sperm concentrations. While fascinating, such a scenario is highly speculative in the absence of field data. An interesting challenge will be to assess what conditions actually prevail during $P$. stolonifera spawning, how these affect rates of sperm dilution, and determine whether eggs from ascidians of different size classes are differentially fertilised in the field. 
Acknowledgements. Thanks to Emma Johnston and 3 reviewers for helpful comments which improved the manuscript.

\section{LITERATURE CITED}

Baynes SM, Howell BR (1996) The influence of egg size and incubation temperature on the condition of Solea solea (L.) larvae at hatching and first feeding. J Exp Mar Biol Ecol 199:59-77

Bennett I, Pope EC (1953) Intertidal zonation of the exposed rocky shores of Victoria, together with a rearrangement of the biogeographical provinces of temperate Australian shores. Aust J Mar Freshw Res 4:105-159

Bertram DF, Strathmann RR (1998) Effects of maternal and larval nutrition on growth and form of planktotrophic larvae. Ecology 79:315-327

Chester CM (1996) The effect of adult nutrition on the reproduction and development of the estuarine nudibranch, Tenellia adspersa (Nordmann, 1845). J Exp Mar Biol Ecol 198:113-130

Coma R, Lasker HR (1997) Effects of spatial distribution and reproductive biology on in situ fertilization rates of a broadcast-spawning invertebrate. Biol Bull 193:20-29

Dalby JE Jr (1995a) Consequences of aggregated living in the ascidian Pyura stolonifera: evidence for non-contact intraspecific competition. Mar Freshw Res 46:1195-1199

Dalby JE Jr (1995b) Ecology of Pyura stolonifera (Urochordata, Ascidiacea) on the central coast of Victoria, Australia. PhD thesis, University of Melbourne, Victoria

Denny MW, Shibata MF (1989) Consequences of surf zone turbulence for settlement and external fertilisation. Am Nat 134:859-889

Denny M, Dairiki J, Distefano S (1992) Biological consequences of topography on wave-swept rocky shores: I. Enhancement of external fertilization. Biol Bull 183: $220-232$

Emlet RB, Hoegh-Guldberg O (1997) Effects of egg size on post-larval performance: experimental evidence from a sea urchin. Evolution 51:141-152

Fairweather PG (1991) A conceptual framework for ecological studies of coastal resources: an example of a tunicate collected for bait on Australian Seashores. Ocean Shoreline Manage 15:125-142

George SB (1994a) Population differences in maternal size and offspring quality for Leptasterias epichlora (Brandt) (Echinodermata: Asteroidea). J Exp Mar Biol Ecol 175: $121-131$

George SB (1994b) The Leptasterias (Echinodermata: Asteroidea) species complex: variation in reproductive investment. Mar Ecol Prog Ser 109:95-98

George SB (1999) Egg quality, larval growth and phenotypic plasticity in a forcipulate seastar. J Exp Mar Biol Ecol 237: 203-224

Hart MW (1995) What are the costs of small egg size for a marine invertebrate with feeding planktonic larvae? Am Nat 146:415-426

Jaeckle WB (1995) Variation in the size, energy content and biochemical composition of invertebrate eggs: correlates to the mode of larval development. In: McEdward L (ed) Ecology of marine invertebrate larvae. CRC, Boca Raton, p $49-79$

Jones HL, Todd CD, Lambert WJ (1996) Intraspecific variation in embryonic and larval traits of the dorid nudibranch mollusc Adalaria proxima (Alder and Hancock) around the northern coasts of the British Isles. J Exp Mar Biol Ecol 202:29-47

Kerrigan BA (1997) Variability in larval development of the tropical reef fish Pomacentrus amboionensis (Pomacentridae): the parental legacy. Mar Biol 127:395-402

Kott P (1997) Tunicates (Sub-Phylum Tunicata). In: Shepherd SA, Davies M (eds) Marine invertebrates of southern Australia, Vol 3. South Australian Research and Development Institute, Adelaide, p 1092-1256

Lambert CC, Lambert $G$ (1981) Formation of the block to polyspermy in ascidian eggs: time course, ion requirements, and the role of accessory cells. J Exp Zool 217: 291-295

Levitan DR (1991) Influence of body size and population density on fertilisation success and reproductive output in a free spawning invertebrate. Biol Bull 181:261-268

Levitan DR (1993) The importance sperm limitation to the evolution of egg size in marine invertebrates. Am Nat $141: 517-536$

Levitan DR (1995) The ecology of fertilisation in free-spawning invertebrates. In: McEdward L (ed) Ecology of marine invertebrate larvae. CRC. Boca Raton, p 123-157

Levitan DR (1996a) Predicting optimal and unique egg sizes in free-spawning marine invertebrates. Am Nat 148: $174-188$

Levitan DR (1996b) Effects of gamete traits on fertilization in the sea and the evolution of sexual dimorphism. Nature 382:153-156

Levitan DR (1998) Does Bateman's principle apply to broadcast-spawning organisms? Egg traits influence in situ fertilisation rates among congeneric sea urchins. Evolution 52:1043-1056

Levitan DR, Petersen C (1995) Sperm limitation in the sea. TREE 10:228-231

Levitan DR, Young CM (1995) Reproductive success in large populations: empirical measures and theoretical predictions of fertilization in the sea biscuit Clypeaster rosaceus. J Exp Mar Biol Ecol 190:221-241

Levitan DR, Sewell MA, Chia FS (1992) How distribution and abundance influence fertilisation success in the sea urchin Strongylocentrotus franciscanus. Ecology 73:248-254

Pennington JT (1985) The ecology of fertilisation of echinoid eggs: the consequences of sperm dilution, adult aggregation, and synchronous spawning. Biol Bull 169:417-430

Podolsky RD, Strathmann RR (1996) Evolution of egg size in free spawners: consequences of the fertilization-fecundity trade-off. Am Nat 148:160-173

Serrao EA, Pearson G, Kautsky L, Brawley SH (1996) Successful external fertilization in turbulent environments Proc Natl Acad Sci 93:5286-5303

Sinervo B, McEdward LR (1988) Developmental consequences of an evolutionary change in egg size: an experimental test. Evolution 42:885-899

Styan CA (1998) Polyspermy, egg size, and the fertilization kinetics of free-spawning marine invertebrates. Am Nat 152:290-287

Styan CA, Butler AJ (in press) Fitting fertilisation kinetic models for free spawning marine invertebrates. Mar Biol

Thomas FIM (1994a) Physical properties of gametes in three species of sea urchins. J Exp Biol 194:263-284

Thomas FIM (1994b) Transport and mixing of gametes in three free-spawning polychaete annelids, Phragmatopoma californica (Fewkes), Sabellania cementarium (Moore) and Schizobranchia insignis (Bush). J Exp Mar Biol Ecol 179:11-27

Underwood AJ (1994) Rocky intertidal shores. In: Hammond LS, Synnot RN (eds) Marine biology. Longman Cheshire, Melbourne, p 274-296

Yund PO (1990) An in situ measurement of sperm dispersal in a colonial marine hydroid. J Exp Zool 253:102-106

Submitted: September 2, 1999; Accepted: January 17, 2000

Proofs received from author(s): March 10, 2000 